\title{
Original Research \\ Characteristics of Drought Disaster-Causing Factor Anomalies in Southwestern and Southern China against the Background of Global Warming
}

\author{
Jinsong Wang', Suping Wang'*, Qiang Zhang', Yiping Li', Jing Wang', Jing Zhang ${ }^{2}$ \\ 'Institute of Arid Meteorology, China Meteorological Administration, \\ Key Open Laboratory of Arid Climatic Change and Disaster Reduction of CMA, \\ Key Laboratory of Arid Climatic Change and Reducing Disaster of Gansu Province, Lanzhou 730020,China \\ ${ }^{2}$ Lanzhou Central Meteorological Observatory, Lanzhou 730020, China
}

Received: May 21, 2015

Accepted: July 6, 2015

\begin{abstract}
In this study, taking drought disaster-causing factors like precipitation, temperature, reference evapotranspiration, and the degree of drought severity based on the drought index as study objects, the characteristics of these above elements against the background of global warming were analyzed by using the method of climate statistics. The data include a variety of climate observations of 129 meteorological stations in southwestern and southern China from 1961 to 2012. The results show that over the past half century sustained temperature increase has been presented in the study area against the background of global warming. However, there is still a sharp warming point (mutation point) of temperature time series that occurred in 1994 during 1961 to 2012 according to the Mann-Kendal test. In other words, the past half century could be divided into two episodes with the year 1994 as the boundary: the first period (i.e. the period before significant temperature rise) from 1961 to 1994, and the second period (i.e. the period after significant temperature rise) from 1995 to 2012. In order to highlight the effects that result from obvious warming, a comparison of the above factors between the two episodes and the trend of these factors in the two episodes are analyzed. This shows that, during the period after significant temperature rise, the study area has experienced a significant downward trend in precipitation and a decline in reference evapotranspiration, but a rise in its change trend, and more serious degree of drought severity due to the impact of less precipitation and higher temperatures.
\end{abstract}

Keywords: drought disaster-causing factors, global warming, anomaly, southwestern and southern China

\section{Introduction}

Global warming has been a hot topic and has drawn widespread attention of scientists. Multiple data analysis results have verified global warming in the $20^{\text {th }}$ century [1-4].

*e-mail: wangjs02@1zu.edu.cn
The $20^{\text {th }}$ century witnessed global warming, which is indisputable, although whether it witnessed the highest temperature in the recent millennium needs to be further confirmed [5]. Since 1950, multiple observed changes have shown that global warming in the past 60 years is beyond doubt [6]. Global warming has brought about severe environmental problems, including a rise in sea level and 
increased natural hazards [7]. For example, Oerlemans [8] estimated that the total area of the world's mountain glaciers would decrease by $1 / 3-2 / 3$ in the $21^{\text {st }}$ century as a result of global warming.

Against the background of global warming, extreme weather and climate events and accompanying disasters have increased in frequency and intensity. Losses caused by meteorological disasters - especially droughts - have consequently been increasing, seriously threatening the sustainable development of the social economy and environment worldwide [9]. Dai [10] pointed out that recent warming has increased atmospheric moisture demand and likely altered atmospheric circulation patterns, both contributing to the drying. In the past decade droughts have occurred more frequently over the world. Drought becomes a main threat to crops, which compromises food production capacity and food security [11]. Research also shows that social, economic, and environmental sustainability can be enhanced by disaster risk management and adaptation approaches [12]. The increased risk of drought duration, severity, and extent is a direct consequence of global warming [13]. Drought risk management can transfer negative exposure and passive adaptation to positive prevention and proactive response, favoring efficient allocation of drought control resources and elimination of the adverse effects of drought [14]. The drought hazards assessment is essential for making mitigation plans to reduce the impact of drought in China $[15,16]$. As a foundation for drought risk management, drought hazard assessment should make clear drought characteristics, including variations in intensity caused by drought disaster-causing factors such as precipitation, temperature, and evaporation, with precipitation as the most direct. It is necessary to analyze characteristics of drought disaster-causing factors and their combined effect so as to achieve drought risk management and enhance the sustainable development of society, economy, and the environment.

Northwestern and northern China have suffered long and frequent drought in the past. However, in recent years southwestern China and the middle and lower Yangtze River regions that used to have abundant precipitation have experienced severe drought, causing enormous economic losses [17-19]. Especially in southwestern China, drought has been increasing and the frequency of extreme drought has risen significantly in the past 50 years [20-24]. The research of He et al. [20] also showed that southwestern China is one of the high drought hazards areas. Against the background of global warming, there is an upward trend in serious and frequent drought, especially in the past decade in southern China $[25,26]$.

All of the above research indicate that drought has occurred frequently not only in northern China, but also in the south. In fact, drought occurs over most parts of the world, even in wet and humid regions [10]. Although drought can occur anywhere, a primary cause of dramatic increase in drought in the past decade in southwestern and southern China may have some connection with global warming. Under global warming conditions, what are the evolution characteristics of drought disaster-causing factors? In this paper, we take southwestern and southern China as the case area, being the area of the greatest occurrence of drought in recent years. Rice planted in southern China accounts for $94 \%$ of the total in sown acreage and $88 \%$ of the total in production in China [11].

Although global temperature increases have become pronounced after the 1970s [27], responses to global warming in regions are different. Degrees of global warming experience are obvious spatial differences in regional distribution [3]. This kind of different regional distribution in temperature is also reflected in China [28]. In order to analyze evolution characteristics of drought disaster-causing factors against the background of global warming, it is necessary to first consider the characteristics of responses to global warming of the study area. In this paper, the period from 1961 to 2012 has been selected as the analysis period, considering the characteristics of time periods and regional differences of responding to warming.

This paper first analyzed the temperature mutation point of the study area in the past half a century and then gave the comparison results of the evolution characteristics of drought disaster-causing factors between the period before and after significant temperature rise.

\section{Data and Method Description}

\section{Study Area and Data}

The study area is situated in southern China (Fig. 1), including Sichuan, Chongqing, Yunnan, Guizhou, Guangxi, and Guangdong provinces. This area is mainly located in the subtropical climate zone, except for northwestern Sichuan and the northernmost part of Yunnan, which are located in the plateau climate zone. In addition, the southern part of Yunnan and Guangdong provinces also belong to a tropical climate zone.

On the whole, the precipitation of the study area increases from the northwest to the southeast. The mean annual precipitation varies from about $500 \mathrm{~mm}$ in the northwest in Sichuan to more than 2,000 $\mathrm{mm}$ in Guangxi and Guangdong along the southern coast. It is worth noting that there is a high-value precipitation area in central Sichuan, where Emei Mountain is located, due to the mountainprecipitation effect. Drought hazards occur frequently in the study area, with one distinct feature in recent years that droughts generally extend over a large area and they can continue for months or years, causing serious and lasting impacts on society and the economy.

This paper selected a variety of climate observations from 129 meteorological stations in the study area (Fig. 1) during 1961 to 2012, including monthly precipitation and monthly average temperature, daily maximum temperature and minimum temperature, sunshine hours, relative humidity, and average wind speed. All the data in this paper are obtained from the National Meteorological Information Center and have passed quality control. 


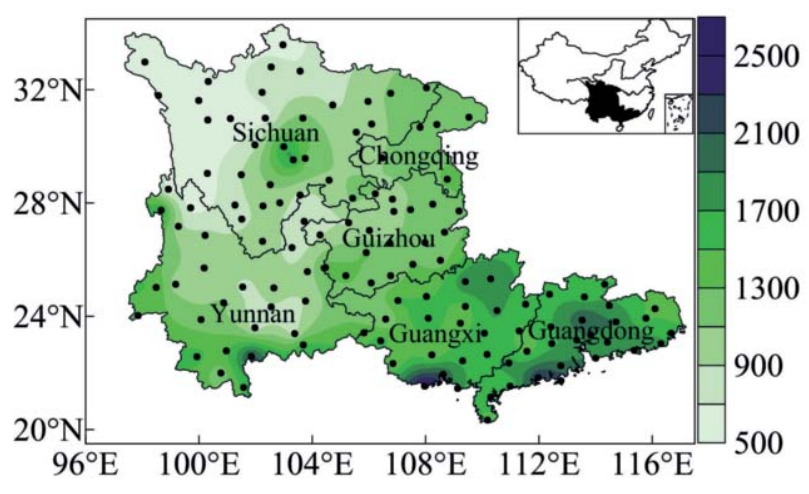

Fig. 1. The location of southwestern and southern areas in China, the spatial distribution of mean annual precipitation $(\mathrm{mm})$, and 129 meteorological stations (solid dots) in the study area.

\section{Methods}

\section{Mann-Kendall Method}

The Mann-Kendall trend test method (referred to as $\mathrm{M}-\mathrm{K}$ ) was adopted to detect sequence trends of climatic elements and to evaluate whether there is a significant discontinuity in data collected over a period of time. It is one of the most widely applied tests to detect the trend and abrupt change of a climate variable. As a nonparametric statistical test, this method is free from compliance with a certain distribution of samples and outlier interference. Characterized by a wide range of detection, less artificiality, and high quantification, focusing on climate sequence mutations, M-K has been widely adopted [29]. The positive value of the $M-K$ test means an increasing trend, and the negative value denotes a decreasing trend. The basic steps can be found in the literature [30].

\section{Trend Coefficient and Variability}

This paper adopted trend coefficient and variability to represent the nature and amplitude of climatic element change, in other words increase or decrease and their respective degree expressed with magnitude, in general, as far as precipitation and temperature are concerned, with the unit of mm.decade ${ }^{-1}$ and ${ }^{\circ} \mathrm{C}$ decade ${ }^{-1}$.

The trend coefficient is calculated as follows:

$$
r_{x t}=\frac{\sum_{i=1}^{n}\left(x_{i}-\bar{x}\right)(i-\bar{t})}{\sqrt{\sum_{i=1}^{n}\left(x_{i}-\bar{x}\right)^{2} \sum_{i=1}^{n}(i-\bar{t})^{2}}}
$$

...where $r_{x t}$ is trend coefficient, $n$ is the length of temporal series (i.e. number of year), $x_{i}$ is the value of climate factor in year $i, \bar{x}$ is the mean value of the samples, and $\bar{t}=(n+1) / 2$ [30].
Climatic variability is actually a linear regression coefficient between climatic factor and time using the least square to estimate:

$$
k=\frac{\sum_{i=1}^{n}\left(x_{i} t_{i}\right)-\frac{1}{n}\left(\sum_{i=1}^{n} x_{i}\right)\left(\sum_{i=1}^{n} t_{i}\right)}{\sum_{i=1}^{n} t_{i}^{2}-\frac{1}{n}\left(\sum_{i=1}^{n} t_{i}\right)^{2}}
$$

...where $x_{i}$ is temporal series of one climatic factor, $t_{i}$ denotes the corresponding time for $x_{i}, n$ is the quantity of samples (i.e. number of year), and $k$ is variability [30].

\section{Penman-Monteith Method}

Reference evapotranspiration refers to the case of evapotranspiration at the sufficient soil moisture condition, reflecting the underlying surface's evapotranspiration ability determined by weather and climate conditions serving as a main factor to be considered in the analysis of drought. Reference evapotranspiration is generally obtained through estimating, and there are many methods for doing so. The FAO Penman-Monteith method was recommended as the sole standard method for the definition and computation of reference evapotranspiration [31]. Also, according to the studies of Gao et al. [32], the FAO Penman-Monteith formula, which is based on the energy balance and water vapor diffusion theory, can reflect the combined effects of various climatic elements applicable to evapotranspiration calculations of areas of different climate types. This paper adopted the FAO Penman-Monteith method to calculate reference evapotranspiration. The specific formula of the FAO Penman-Monteith method as well as the selection of some parameters can be found as follows:

The equation of reference evapotranspiration from Allen et al. [31] is defined as:

$$
E T_{0}=\frac{0.408 \Delta\left(R_{n}-G\right)+\gamma \frac{900}{T+273} U_{2}\left(e_{s}-e_{a}\right)}{\Delta+\gamma\left(1+0.34 U_{2}\right)}
$$

...where $E T_{0}$ is the reference evapotranspiration $\left(\mathrm{mm} \cdot \mathrm{day}^{-1}\right)$, $R_{n}$ is the net radiation at the crop surface $\left(\mathrm{MJ} \cdot \mathrm{m}^{-2} \cdot \mathrm{day}^{-1}\right)$, $G$ is the soil heat flux density $\left(\mathrm{MJ} \cdot \mathrm{m}^{-2} \cdot \mathrm{day}^{-1}\right), T$ is the mean daily air temperature at $2 \mathrm{~m}$ height $\left({ }^{\circ} \mathrm{C}\right), U_{2}$ is the wind speed at $2 \mathrm{~m}$ height $\left(\mathrm{m} \cdot \mathrm{s}^{-1}\right), e_{s}$ is the saturation vapour pressure $(\mathrm{kPa}), e_{a}$ is the actual vapour pressure $(\mathrm{kPa}), e_{s}-e_{a}$ is the saturation vapour pressure deficit $(\mathrm{kPa}), \Delta$ is the slope of saturation vapour pressure curve at air temperature $T$ $\left(\mathrm{kPa} \cdot{ }^{\circ} \mathrm{C}^{-1}\right)$, and $\gamma$ is the psychrometric constant $\left(\mathrm{kPa}^{\circ}{ }^{\circ} \mathrm{C}^{-1}\right)$.

Significantly, as the magnitude of the day soil heat flux beneath the grass reference surface is relatively small, it may be ignored and thus:

$$
G \approx 0
$$

For the other details, expressions are given by: 


$$
\begin{gathered}
R_{n}=(1-0.23) R_{s}-\sigma\left[\frac{T_{\mathrm{max}, k}^{4}+T_{\mathrm{min}, k}^{4}}{2}\right] \times \\
\left(0.34-0.14 \sqrt{e_{a}}\right)\left(1.35 \frac{R_{s}}{R_{s o}}-0.35\right) \\
e_{s}=\frac{e^{\circ}\left(T_{\max }\right)+e^{\circ}\left(T_{\min }\right)}{2} \\
e^{\circ}(T)=0.6108 \mathrm{exp}\left[\frac{17.27 T}{T+237.3}\right] \\
e_{a}=\frac{R H_{\text {mean }}}{100} e_{s} \\
U_{2}=U_{10} \frac{4.87}{\ln (67.8 \times 10-5.42)}
\end{gathered}
$$

...where $\sigma$ is Stefan-Boltzmann constant $\left(\mathrm{MJK}^{-4} \cdot \mathrm{m}^{-2} \cdot \mathrm{day}^{-1}\right)$, $T_{\max , k}$ and $T_{\min , k}$ are the maximum and the minimum daily air temperatures in kelvin units at $2 \mathrm{~m}$ height $(\mathrm{K})$, respectively; $R_{s}$ is the solar or shortwave radiation $\left(\mathrm{MJ} \cdot \mathrm{m}^{-2} \cdot\right.$ day $\left.^{-1}\right) ; R_{s o}$ is the clear-sky solar radiation $\left(\mathrm{MJ} \cdot \mathrm{m}^{-2} \cdot \mathrm{day}^{-1}\right) ; T_{\max }$ and $T_{\min }$ are the maximum and the minimum daily air temperature at $2 \mathrm{~m}$ height $\left({ }^{\circ} \mathrm{C}\right)$ respectively; $R H_{\text {mean }}$ is the daily relative humidity (\%); and $U_{10}$ is the wind speed at $10 \mathrm{~m}$ height $\left(\mathrm{m} \cdot \mathrm{s}^{-1}\right)$.

\section{K Drought Index Calculation}

The degree of drought severity is expressed with $K$ drought index, which has been well applied in northwestern China and the Yellow River basin [33, 34], while its application in southern China is analyzed in another paper [35]. In the above literature, comparative analysis of drought monitoring effects of different drought indices highlighted the advantages of $K$ drought index in drought monitoring of different areas.

The $K$ drought index is defined as:

$$
K_{i, j}=R_{i, j}^{\prime} / E_{i, j}^{\prime}
$$

...where $K_{i, j}$ is the $K$ drought index; $R_{i, j}^{\prime}$ and $E_{i, j}^{\prime}$ are the relative variability rate of precipitation and reference evapotranspiration in an appointed period time, respectively; $i$ denotes the year number, and $j$ denotes the meteorological station number.

The $R_{i, j}^{\prime}$ is given by:

$$
R_{i, j}^{\prime}=R_{i, j} / R_{p j}
$$

...where $R_{i, j}$ is the precipitation in an appointed period time and $R_{p j}$ is the latest 30-year average value of precipitation (i.e. normal climate) of an appointed time period.
Table 1 . The categories of drought severity about $K$ index.

\begin{tabular}{|c|c|c|}
\hline Category & Drought description & Percentile chance (\%) \\
\hline 1 & No drought & $>30$ \\
\hline 2 & Incipient drought & 15 to $\leq 30$ \\
\hline 3 & Moderate drought & 5 to $\leq 15$ \\
\hline 4 & Severe drought & 2 to $\leq 5$ \\
\hline 5 & Extreme drought & $\leq 2$ \\
\hline
\end{tabular}

The $E_{i, j}^{\prime}$ is given by:

$$
E_{i, j}^{\prime}=E_{i, j} / E_{p j}
$$

...where $E_{i, j}$ is the reference evapotranspiration in an appointed period and $E_{p j}$ is the latest 30-year average value of reference evapotranspiration (i.e. climate normal) of an appointed period.

Following the approach of Svoboda et al. [36], the classification of drought severity of $K$ index is divided into five levels according to the percentile method (Table 1). Each category is associated with its percentile chance of happening in any given year out of the study period from 1961 to 2012.

\section{Results and Analysis}

\section{Characteristics of Responses to Global Warming in Southwestern and Southern China}

Using the M-K method, this paper tested the trend and mutation of the annual average temperature sequence of 129 meteorological stations in southwestern and southern China during 1961 to 2012. As shown in Fig. 2, the overall temperature of the study area has increased in the past half century. Before 1970, fluctuations appeared in temperature, with alternate rises and falls in inter-annual terms. After 1970, temperature experienced a rise in the fluctuation situation with the latter particularly significant after 1986. Clearly, the response to global warming of the study area is obvious, namely consistent with the global average temperature rise.

Although Fig. 2 shows that the past half century has displayed a constant temperature rise in southwestern and southern China, a mutation occurred in 1994 (UF and UB intersection in Fig. 2) and a more significant temperature rise after 1994, serving as a period with significant temperature rise in the past half century. Taking 1994 as a boundary, we divided the period of 1961 to 2012 into two episodes: the first from 1961 to 1994 (i.e., the period before significant temperature rise) and the second from 1995 to 2012 (i.e., the period after significant temperature rise). Thus, in order to highlight the impact of significant warming, the following will use contrastive analysis to study the new evolution features of drought disaster-causing factors under climate warming and describe the impact of the new characteristics on the development of drought. 


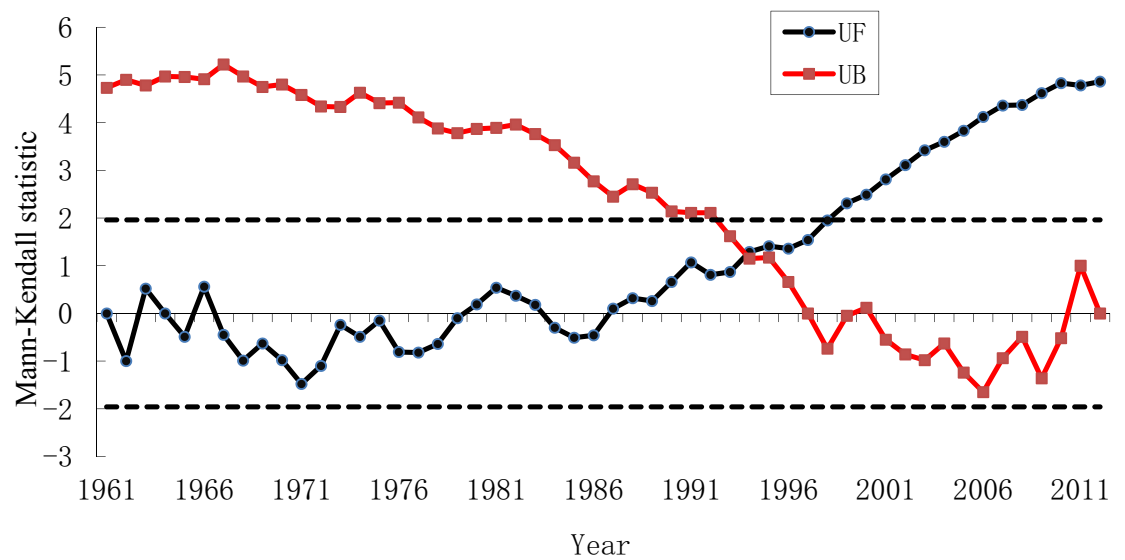

Fig. 2. The annual mean temperature of southwest and south China between 1961 and 2012 by the Mann-Kendall test. The dashed at $y= \pm 1.96$ are the significance standard borderlines of $\alpha=0.05$. UF: analysis of the temperature anomaly values from 1961 to 2012 . UB: analysis of the temperature anomaly values from 2012 retrograde to 1961. Graphical analysis is conducted for UF and UB to identify the intersection of the curves, thus allowing detection of the initiation of a trend or change. The point of intersection of the two curves UF and UB in 1994 indicates initiation of a sharp warming trend.

\section{Analysis of Drought Disaster-Causing Factor Characteristics before and after Significant Temperature Rises}

The direct cause for drought occurrence (or relief) is the shortage (or increase) of precipitation. In case the increase in precipitation fails to offset the increase in evaporation, it will be difficult to relieve the drought. In the case of a decrease in precipitation accompanied by an increase in evaporation, it will exacerbate drought. Therefore, in considering drought disaster-causing factors, precipitation and evaporation should be the most basic elements.

To highlight the impact of temperature rise, as described in section 3.1, this paper took the year 1994 as the boundary to divide the period from 1961 to 2012 into 2 periods: the first period (1961 to 1994), and the second period (1995 to 2012), with the first as the pre-significant temperature rise period and the second as the post-temperature rise period, analyzing the differences between annual precipitation, temperature, and reference evapotranspiration of the two periods so as to explore the variation characteristics of drought disaster-causing factors after the significant temperature rise and the impact of significant temperature rise on drought disaster-causing factors.

\section{Variation Characteristics of Precipitation}

before and after Significant Temperature Rise

Most areas of southwestern and southern China experienced less annual average precipitation during the period after significant temperature rise from 1995 to 2012 than that during the period before significant temperature rise from 1961 to 1994 (Fig. 3), centering on central and southern Sichuan, north Chongqing, east Yunnan, west Guizhou, central Guangdong, north and southwest Guangxi, with decrease values from 120 to $220 \mathrm{~mm}$, while west Sichuan, central Yunnan, east Guangxi, and south and north Guangdong saw a certain increase. Fig. 3 shows that most of the study area clearly experienced less precipitation after the temperature rise.

Fig. 4 shows the precipitation variation trends of the study area before and after the period of significant temperature rise. In terms of distribution, the range of precipitation decrease was more than that of precipitation increase before the period of significant temperature rise (Fig. 4a). However, the precipitation decrease trend of most areas failed to pass the confidence level test with credibility of $95 \%$. Compared with the period prior to the significant temperature rise, precipitation variation in most areas in the period after the significant temperature rise showed a downward trend (Fig. 4b), except for northwest Yunnan, northeast Chongqing, and southern Sichuan and Guangdong, which witnessed the contrary, with northeast Sichuan experiencing a slight rise, consistent with the precipitation variation in the period prior to the significant temperature rise. Different characteristics lie in the fact that after the significant temperature rise, a downward trend in precipitation in most areas passed the confidence level test with credibility of $95 \%$. Precipitation in a small area in northeast Sichuan experienced an obvious increase.

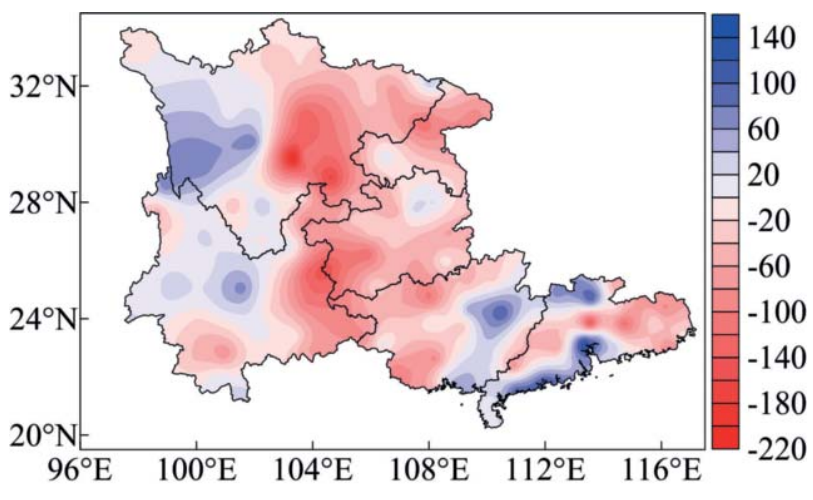

Fig. 3. Difference of mean annual precipitation between periods of 1995-2012 and 1961-1994 in southwestern and southern China (unit: $\mathrm{mm}$ ). 

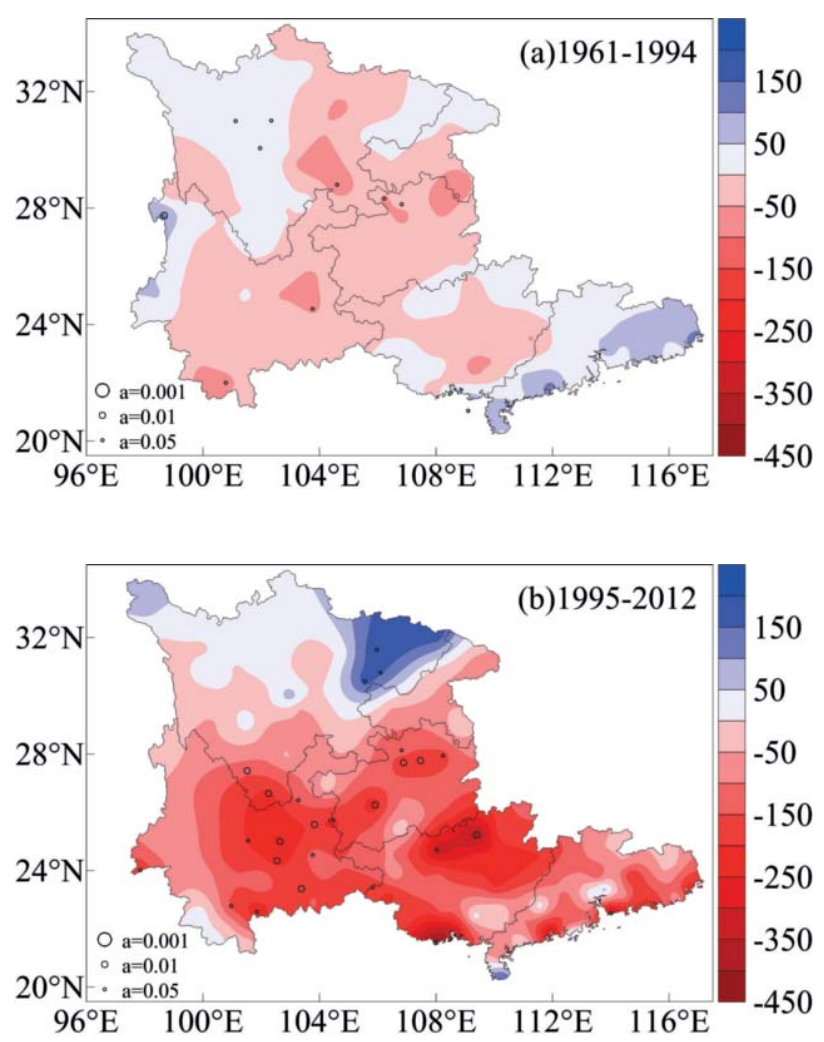

Fig. 4. Trend ratio of annual precipitation during the period before (a) and after (b) 1994 in southwestern and southern China (unit: $\left.\mathrm{mm} \cdot \mathrm{decade}^{-1}\right)$. (Symbols $\bigcirc, \circ$, and $\circ$ in figures mean the trend ratio passed the significant test at $0.001,0.01$, and 0.05 levels, respectively.)

However, all other areas of southwest and south China witnessed a decrease, centering on north Guangxi (as little as $450 \mathrm{~mm} \cdot$ decade $\left.^{-1}\right)$, and then south Sichuan, east-central and south Yunnan, and west and north Guizhou, as little as 150$350 \mathrm{~mm} \cdot$ decade $^{-1}$, in other words, after the significant temperature rise, precipitation in most areas of southwest and south China experienced a significant decrease.

Analysis in combination with Figs. 3 and 4 shows that temperature rise made the precipitation decrease more significant in the study area. East Yunnan, west Guizhou, and north Guangxi experienced a large precipitation decrease amplitude and an obvious downward trend in precipitation, in other words making these areas show the most serious precipitation decrease.

\section{Distribution of Average Temperature before and after Significant Temperature Rise}

Over the past half century, the average temperature of the study area has shown a rise as a whole, with mutation in 1994 and then illustrating a significant temperature rise (Fig. 2). However, in terms of the spatial variation distribution before and after the significant temperature rise (Fig. 5), in either case temperature in some areas also showed a downward trend. The range of the downward trend of temperature before the significant temperature rise was clearly greater than that after the significant temperature rise, indicating that over the past half century, the overall temperature rise of the study area mainly depended on a significant temperature rise after 1994. We can see from Fig. 5a that after the significant temperature rise, northeast Sichuan, southwest Guangxi, and most parts of Guangdong illustrated a temperature drop. And the rest of the areas displayed an obvious temperature rise.

The difference in temperature during 1995 to 2012 and 1961 to 1994 (Fig. 6) showed the temperature in the whole area as a positive value, demonstrating that the temperature of southwest and south China was clearly higher in the period after significant temperature rise than that in the period before significant temperature rise, indicating that southwest and south China have experienced serious impacts of global warming since 1994.

\section{Reference Evapotranspiration Variation} before and after the Significant Temperature Rise

It is shown in Fig. 7a that there is a downward trend of reference evapotranspiration in the period before significant temperature rise in southwest and south China, except a small area of southwest and north Sichuan and west Yunnan, and the downward trend of reference evapotranspiration in most areas passed the confidence level test with
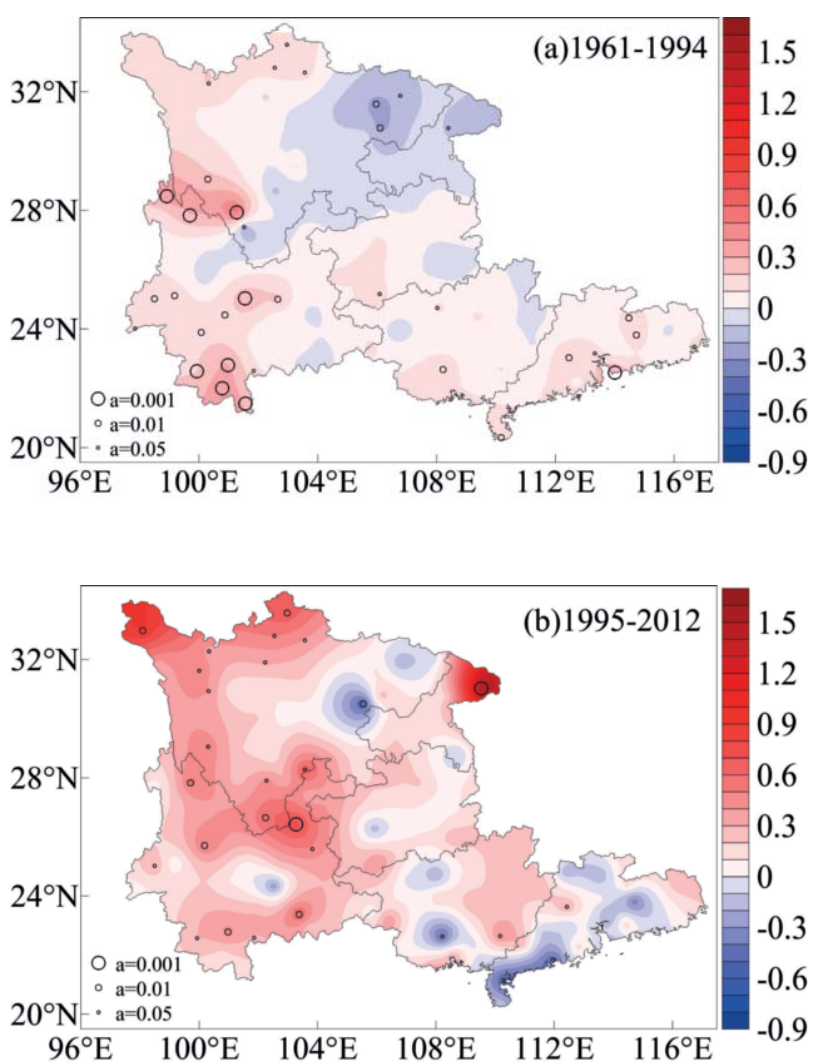

Fig. 5. Trend ratio of annual mean temperatures during the period before (a) and after (b) 1994 in southwestern and southern China (unit: ${ }^{\circ} \mathrm{C} \cdot$ decade $\left.^{-1}\right)$. (Symbols $\bigcirc, \circ$, and $\circ$ in figures mean the trend ratio passed the significant test at $0.001,0.01$, and 0.05 levels, respectively.) 


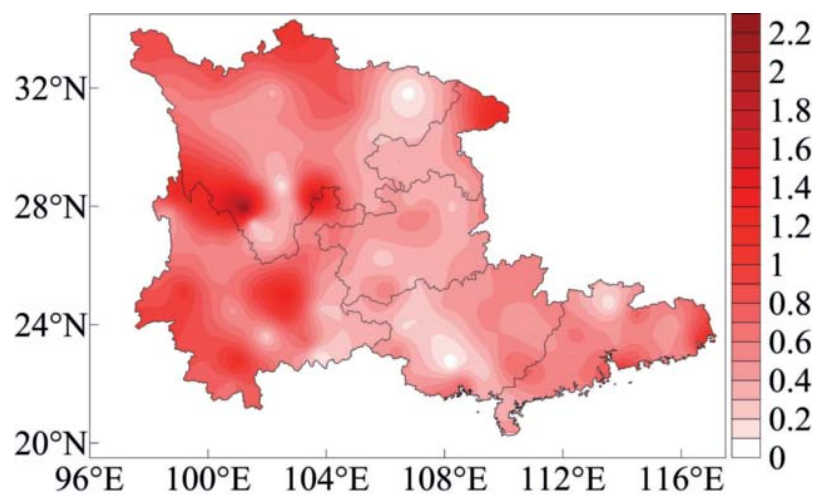

Fig. 6. Difference of average annual mean temperatures between periods of 1995-2012 and 1961-1994 in southwestern and southern China (unit: ${ }^{\circ} \mathrm{C}$ ).

credibility of $99 \%$, presenting that before the significant temperature rise, reference evapotranspiration had significantly dropped in the study area, with the largest decreasing value of $50 \mathrm{~mm} \cdot \mathrm{decade}^{-1}$, centering on the eastern part of the study area. In the period after significant temperature rise (Fig. 7b), except for a few places, the reference evapotranspiration variation experienced growth that passed the confidence level test with credibility of $95 \%$, and $99 \%$ in northeast and west Yunnan and south Guangxi, showing a significant temperature rise in reference evapotranspiration variation, with the largest value reaching $90 \mathrm{~mm} \cdot \mathrm{decade}^{-1}$, centering on Guangxi in the west and Yunnan in the east of the study area and north Guangdong.

Over the past half century, reference evapotranspiration has generally witnessed a downward trend (Fig. 7c) except in southwest Yunnan, southwest and north Sichuan, and east Guangdong displaying an upward trend, in other words, the continual temperature rise over the past half century has failed to increase reference evapotranspiration in southwest and south China. According to the study results of Ren et al. [37], the direct influencing factors on evaporation are elements such as sunshine hours, average wind speed, and daily range of temperature evaporation, and then the significant temperature rise. Liu et al. [38] pointed out that the observed pan evaporation and simulated actual evaporation also demonstrated a downward trend from 1960 to 2005 in southwest and south China. According to the comparative analysis between the results of this paper and that of the previous research, we can see that reference evapotranspiration variation characteristics of the study area over the past half century obtained by this paper through analysis are consistent with the results obtained by previous studies.

As can be seen from Fig. 8, the difference of reference evapotranspiration between the period before and after significant temperature rise was positive in southwest Yunnan (bordering Yunnan and Sichuan), and east and south Guangdong, with its distribution basically consistent with the range of reference evapotranspiration rise over the past half a century (Fig. 7c), indicating that in the period after 1994, namely the significant temperature rise period, the distribution of the areas with larger reference evapotranspiration determined the distribution range of reference evapotranspiration rise of the study area over the past half a century. However, most of the areas in Fig. 8 showed a negative value, indicating that the average annual reference evapotranspiration in the period after the significant temperature rise, in most areas of southwest and south China, was less than that of the period before the significant temperature rise. Fig. 8 shows the drought magnitude decreased by 30-110 mm, centering on northwest Sichuan, which decreased by $110 \mathrm{~mm}$.
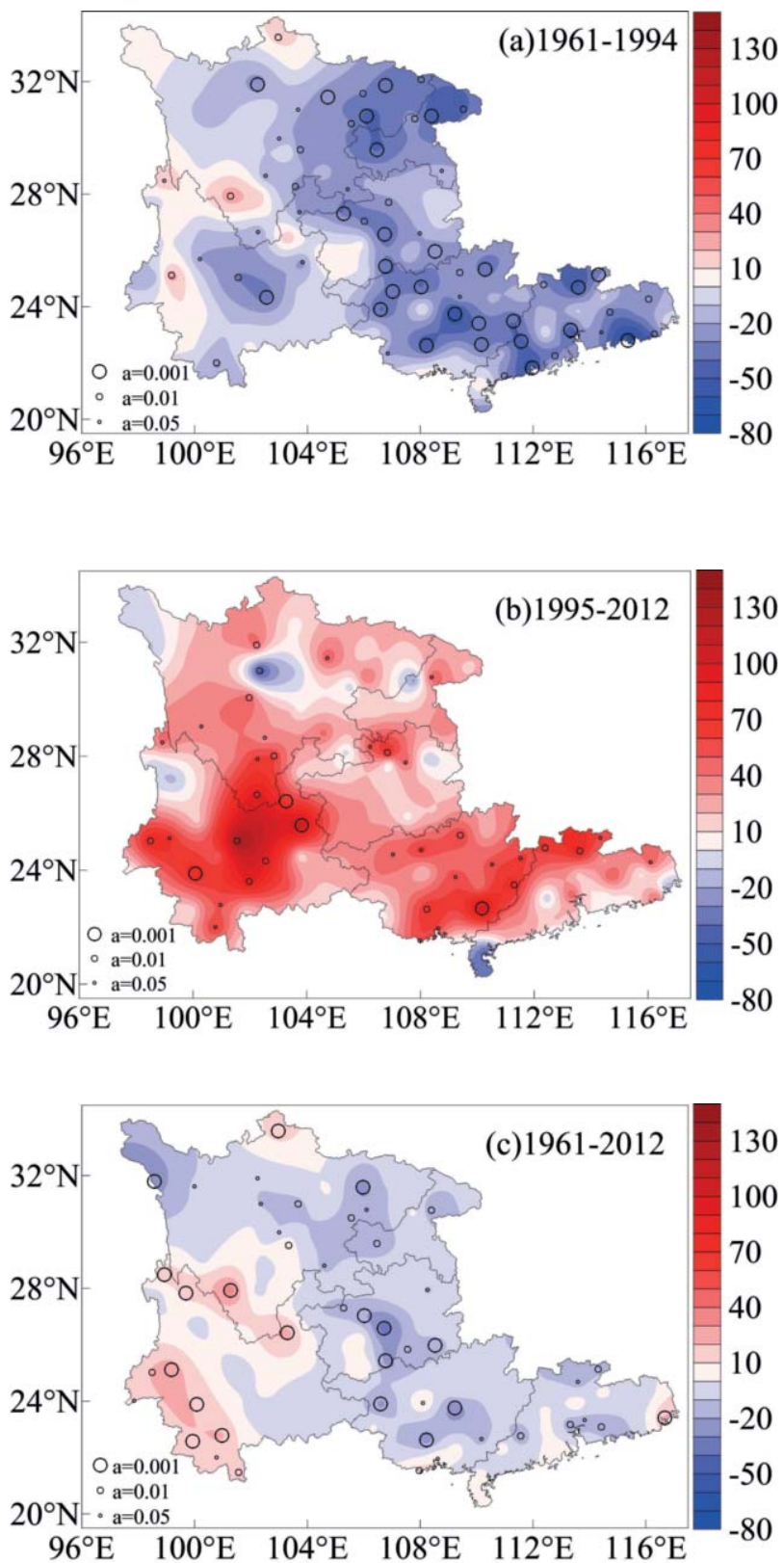

Fig. 7. Trend ratio of annual reference evapotranspiration during the period before (a) and after (b) 1994, and (c) from 1961 to 2012 in southwestern and southern China (unit: $\mathrm{mm} \cdot \mathrm{decade}^{-1}$ ). (Symbols $\bigcirc, \circ$, and $\circ$ in figures mean the trend ratio passed the significant test at $0.001,0.01$, and 0.05 levels, respectively.) 


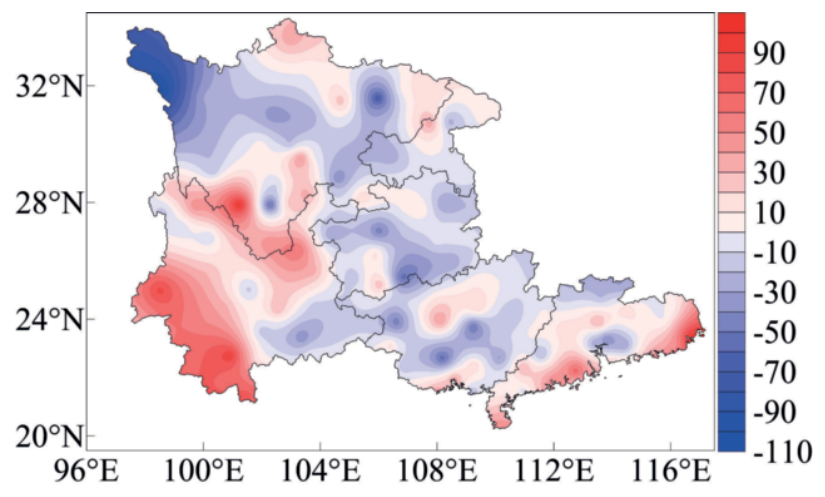

Fig. 8. Difference of mean annual reference evapotranspiration between 1995-2012 and 1961-1994 in southwestern and southern China (unit: $\mathrm{mm}$ ).

\section{Degree of Drought Severity Evolution Characteristics before and after Significant Temperature Rise}

Global warming not only raises temperatures, but also enhances drying near the surface, as is captured by the PDSI [39]. How about the drought evolution in southwest and south China against global warming? Based on the $K$ drought index, this paper calculated the monthly $K$ value and analyzed the variation trend of the degree of drought severity from January to December in the period before and after significant temperature rise (Fig. 9). The greater the drought grade is, the higher the degree of drought severity. The positive variation in the figures expresses an increasingly high degree of drought severity. The difference between the degree of drought variation trends before and after significant temperature rise was characterized by the factors outlined below.

According to the characteristics of temporal change, we can see from Fig. 9 that there has been a marked shift in drought intensity between the two episodes, namely the period after 1994 (i.e. the period after significant temperature rise) and the period before 1994 (i.e. the period before significant temperature rise). These distinct differences were demonstrated in all months except April and September, which only showed a slight difference, with February, March, July, August, November, and December showing the greatest change. The degree of drought became more severe in most areas after the temperature rise, centering on February, March, July, and August in the southern part of the study area. As far as November and December are concerned, the degree of drought was more serious in the northern and western parts of the study area. In January, May, June and October, drought intensity variation was significantly different before and after significant temperature rise and the distribution of drought aggravation and mitigation was also different. No consistent distribution variation rule was available.

From the characteristics of spatial change, we can also see from Fig. 9 that there was an upward trend in drought intensity in most parts of the study area after the significant temperature rise. There are different features of the change in the trend in the degree of drought severity in different regions in the study area. In Sichuan and Chongqing, drought intensity showed an upward trend all year round after the significant temperature rise, except for May and July. In Yunnan, drought intensity showed a marked increase in all months after the significant temperature rise except for January and April. In Guizhou, drought intensity experienced a change in the trend upwards in all the months after the significant temperature rise except for April and December. In Guangxi, drought intensity rose in all months after the significant temperature rise except for June, November, and December. In Guangdong, drought intensity showed a downward tendency after the significant temperature rise in January, May, June, October, and November, and upward in the rest of the months. So we can see from the above analyses that the months with significant marked increases in drought intensity are different for the different areas. However, it was common that after the significant temperature rise - in February, March, July, and August - the degree of drought severity was aggravated obviously in Yunnan, Guizhou, Guangxi, and Guangdong, which is located in the south of the study area. And in January, November, and December, the degree of drought became more serious in Sichuan and Chongqing - all located in the northern part of the study area. The above-mentioned different distribution of the degree of drought severity in the different regions against the background of global warming revealed that a change in the trend of the degree of drought severity is distinct in northern and southern regions in the study area. Although regional differences in the degree of drought severity exist, the underlying conditions of warming more easily leads to droughts. This result is consistent with the result obtained by Song et al. [40].

\section{Conclusions}

The above contrastive analysis on drought disastercausing factors of the study area, including precipitation, temperature, reference evapotranspiration, and drought intensity, variation characteristics before and after the significant temperature rise, indicate that the sharp rise of temperature has significantly decreased precipitation, centering on east Yunnan, west Guizhou, and north Guangxi, and making reference evapotranspiration magnitude decrease and variation trend increase in the period after the sharp temperature rise. The intensity variation trend of the degree of drought severity expressed by the drought index indicates that drought becomes serious with temperature rise. The basic definition of the drought index shows that drought will be further aggravated under the impact of less precipitation and higher temperatures.

It should be emphasized that multiple research results show that against the background of a rise in temperature, reference evapotranspiration variation has decreased [32, $37,38]$. Analysis results of this paper also point out that the reference evapotranspiration variation trend over the past half century has decreased, which is consistent with the 

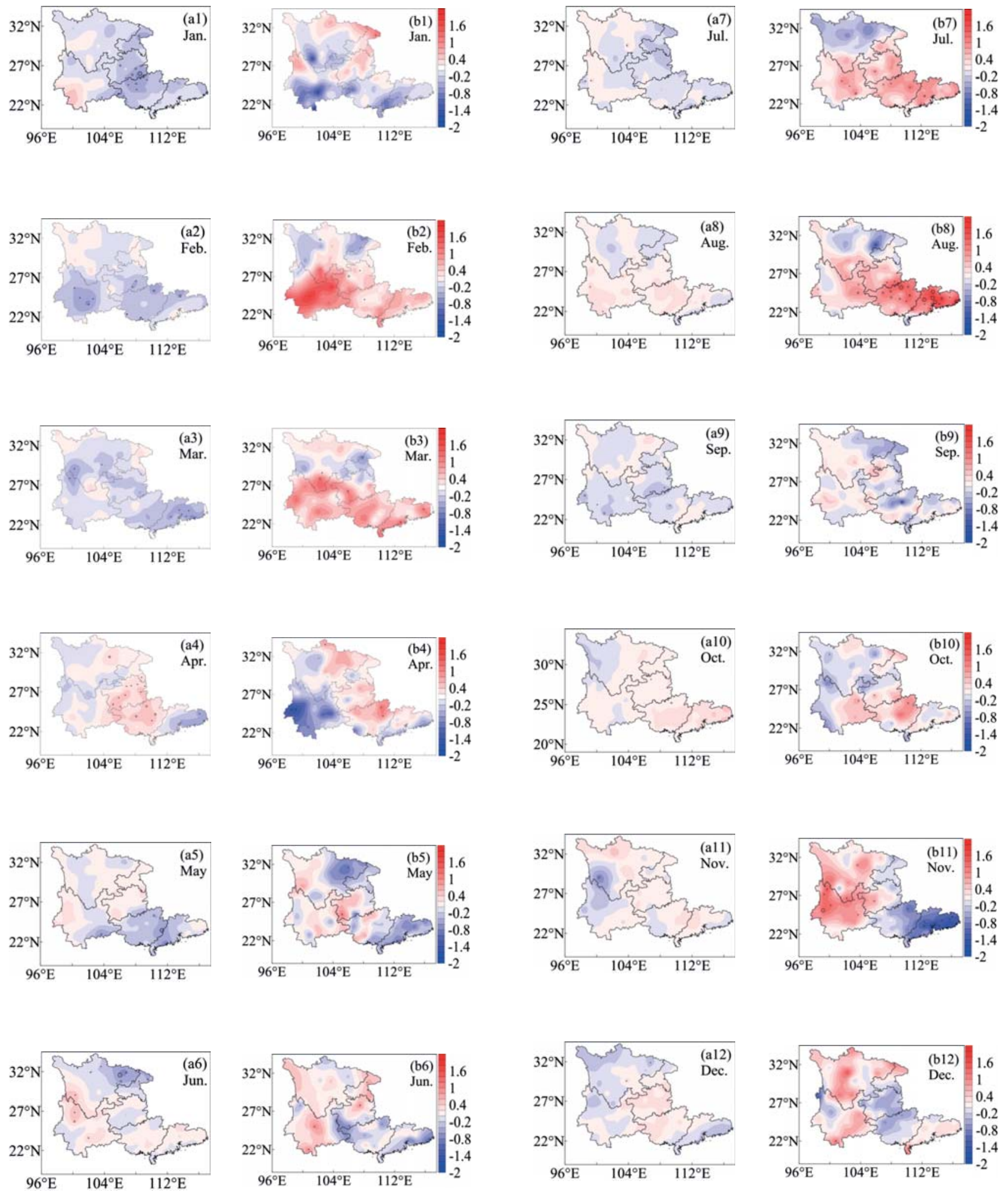

Fig. 9. Trend ratio of monthly degree of drought severity defined by K drought index during the period before (a1-a12) and after (b1-b12) 1994 in southwestern and southern China. The symbols a1 to a12 on the top right corner of the figures indicate the different months in the period during 1961 to 1994 (a1 means in January, a2 means in February, a3 means in March, etc.). The symbols b1 to b12 are the same as a1 to a12, but for 1995 to 2012. Red shade: the degree of drought severity has aggravated the trend. Blue shade: the degree of drought severity has alleviated the trend. Symbols $\bigcirc, \circ$, and $\circ$ in figures mean the trend ratio passed the significant test at $0.001,0.01$, and 0.05 level, respectively. 
results obtained by the previous studies. However, in the warmer period after 1994, the reference evapotranspiration trend in the study area increased, which is inconsistent with the results obtained by previous studies. We think that two issues exist: Firstly, although the impact of the continual significant temperature rises on evaporation is secondary [37], the reference evapotranspiration increase indicated in the study area originates from the warmer period after the temperature sharp warming point. So, will the more dramatic temperature rise have an important effect and influence on reference evapotranspiration? This problem should be discussed in the future. Secondly, this article reaches the conclusion that reference evapotranspiration increases in the significant temperature rise period, which may be closely related to the study time interval. To highlight the temperature rise influence based on the $\mathrm{M}-\mathrm{K}$ test, this paper found the temperature mutation point occurred in 1994. Taking the year 1994 as the boundary, this paper took the period during 1995 to 2012 as the significant temperature rise period. Thus, the reference evapotranspiration in this paper refers to the significant temperature rise period, namely the period during 1995 to 2012, in other words a very limited period. It is necessary to conduct further analysis with the follow-up data so as to determine the credibility of the upward trend in reference evapotranspiration against the background of a sharp rise in temperature. This problem has yet to be studied further.

\section{Acknowledgements}

The authors are grateful to the National Meteorological Information Center of CMA for providing the data used in this study. We also thank the reviewers and editors for helpful comments and suggestions that improved the manuscript. This research was supported by the National (Key) Basic Research and Development (973) Program of China (Grant No. 2013CB430200).

\section{References}

1. BRADLEY R. 1000 Years of climate change. Science. 288, 1353, 2000.

2. HANSEN J., RUEDY R., SATO M., IMHOFF M., LAWRENCE W., EASTERLING D., PETERSON T., KARL T. A closer look at United States and global surface temperature change. J. Geophys. Res. 106, 23947, 2001.

3. JONES P.D., MOBERG A. Hemispheric and large-scale surface air temperature variations: An extensive revision and an update to 2001. J. Climate. 16, 206, 2003.

4. MANN M.E., JONES P.D. Global surface temperatures over the past two millennia. Geophys. Res. Lett. 30, (15), $1820,2003$.

5. WANG S.W., LUO Y., ZHAO Z.C., WEN X.Y., HUANG J.B. Debates on the cause of global warming. Adv. Climate Change Res. 7, (2), 79, 2011.

6. SHEN Y.P., WANG G.Y. Key findings and assessment results of IPCC WGI fifth assessment report. J. Glaciol. Geocryol. 35, (5), 1068, 2013 [In Chinese].
7. HE Y.Q., LI Z.X., YANG X.M., JIA W.X., HE X.Z., SONG B., ZHANG N.N., LIU Q. Changes of the Hailuogou Glacier, Mt. Gongga, China, against the Background of Global Warming in the Last Several Decades. J. China Univ. Geosci. 19, (3), 271, 2008.

8. OERLEMANS J. Quantifying global warming from the retreat of glaciers. Science. 264, 243, 1994.

9. WILHITE D.A. Drought as a Natural Hazard: Concepts and Definitions. In: WILHITE D.A., (Eds.) Drought: A Global Assessment, London: Routledge, 3, 2000.

10. DAI A.G. Drought under global warming: a review. Wiley Interdisciplinary Reviews: Climate Change. 2, 45, 2011.

11. MA X., WU S.H., LI Y.E., ZHANG X.Y., GAO Q.Z., WU Y. Rice re-cultivation in southern China: An option for enhanced climate change resilience in rice Production. J. Geogr. Sci. 23, (1), 67, 2013.

12. FIELD C. B., BARROS V., STOCKER T.F., QIN D.H., DOKKEN D.J., EBI K.L., MASTRANDREA M. D., MACH K. J., PLATTNER G.K., ALLEN S. K., TIGNOR M., MIDGLEY P. M. (Eds.) IPCC, Summary for Policymakers. In:Intergovernmental Panel on Climate Change Special Report on Managing the Risks of Extreme Events and Disasters to Advance Climate Change Adaptation, Cambridge University Press, Cambridge, United Kingdom and New York, NY, USA, pp. 740, 2011.

13. TRENBERTH K. E., DAI A.G., RASMUSSEN R.M., PARSONS D.B. The changing character of precipitation. Bull. Amer. Meteor. Soc. 84, 1205, 2003.

14. ZHANG Q., ZHANG L., CUI X.C., ZENG J. Progresses and challenges in drought assessment and monitoring. Adv. Earth Sci. 26, (7), 763, 2011 [In Chinese].

15. HE B., LV A.F., WU J.J., ZHAO L., LIU M. Drought hazard assessment and spatial characteristics analysis in China. Journal of Geographical Sciences. J. Geogr. Sci. 21, (2), 235, 2011.

16. SU Y., YIN J., SHEN H. Social perception and response to the drought process: a case study of the drought during 2009-2010 in the Qianxi'nan Prefecture of Guizhou Province. Nat. Hazards. 64, (1), 839, 2012.

17. YANG S.Y., WU B.Y., ZHANG R.H., ZHOU S.W. Relationship between an abrupt drought-flood transition over mid-low reaches of the Yangtze River in 2011 and the intraseasonal oscillation over mid-high latitudes of East Asia. Acta Meteor. Sinica. 27, (2), 129, 2013.

18. WANG S.P., DUAN H.X., FENG J.Y. The influence and cause of drought in China in spring in 2011. J. Arid Meteor. 29, (2), 261, 2011 [In Chinese].

19. WANG J.S., HAYES MICHAEL J. Improving Communication and Collaboration for Drought Vulnerability Analysis in China. Disaster Adv. 6, (1), 71, 2013.

20. HE J.Y., ZHANG M.J., WANG P., WANG S.J.,WANG X.M. Climate characteristics of the extreme drought in Southwest China during recent 50 years. Acta Geogr. Sinica. 66, (9), 1179, 2011 [In Chinese].

21. MA Z.F., LIU J., ZHANG S.Q., CHEN W.X., YANG S.Q. Observed climate changes in Southwest China during 19612010. Adv. Climate Change Res. 4, (1), 30, 2013.

22. ZHANG M.J., HE J.Y., WANG B.L., WANG S.J., LI S.S., LIU W.L., MA X.N. Extreme drought changes in Southwest China from 1960 to 2009. J. Geogr. Sci. 23, (1), 3, 2013.

23. ZHANG X.Q., YAMAGUCHI Y. Characterization and evaluation of MODIS-derived Drought Severity Index (DSI) for monitoring the 2009/2010 drought over southwestern China. Nat. Hazards. 74, (3), 2129, 2014. 
24. ZHENG J.M., ZHANG W.C., WAN Y.X.,DUAN X. Comparative analysis on abnormal circulation in spring in extreme drought year of Yunnan. Plateau Meteor. 32, (6), 1665, 2013 [In Chinese].

25. LI W.G., HOU M.T., CHEN H.L., CHEN X.M. Study on drought trend in South China based on standardized precipitation evapotranspiration index. J. Nat. Disa. 21, (4), 84, 2012 [In Chinese].

26. YANG P., XIAO Z.N., YANG J., LIU H. Characteristics of clustering extreme drought events in China during 19612010. Acta Meteor. Sinica. 27, (2), 186, 2013.

27. FOLLAND C. K., KARL T.R. Coauthors, Observed climate variability and change. Climate Change 2001: The Scientific Basis, J. T. Houghton et al., (Eds.), Cambridge University Press, pp. 99-181, 2001.

28. WANG Z.Y., DING Y.H., ZHANG Q., SONG Y.F. Changing trends of daily temperature extremes with different intensities in China. Acta Meteor. Sinica. 26, (4), 399, 2012.

29. FU C.B., WANG Q. The definition and detection of the abrupt climatic change. Chinese J. Atmos. Sci. 16, (4), 482, 1992.

30. WEI F.Y. Climate Statistical Diagnosis and Forecast technology. Meteorological Press, Beijing, pp. 296, 2007 [In Chinese].

31. ALLEN R.G., PEREIRA L.S., RAES D., SMITH M. Crop evapotranspiration: guidelines for computing crop water requirements. Irrigation and Drainage Paper 56, FAO, Rome, 1998.

32. GAO G., CHEN D.L., REN G.Y., CHEN Y., LIAO Y.M.
Trend of potential evapotranspiration over China during 1956 to 2000. Geogr. Res. 25, (3), 378, 2006 [In Chinese].

33. WANG J.S., GUO J.Y., QING J.Z. Application of a kind of $\mathrm{K}$ drought index in the spring drought analysis in Northwest China. J. Nat. Resour. 22, (5), 709, 2007 [In Chinese].

34. WANG J.S., LI Y.P., REN Y.L., LIU Y.P. Comparison among several drought indices in the Yellow River valley. J. Nat. Resour. 28, (8), 1337, 2013 [In Chinese].

35. WANG S.P., WANG J.S., ZHANG Q., LI Y.P., WANG Z.L. Applicability evaluation of drought indices in monthly scale drought monitoring in southern China. Plateau Meteor. 2015 [In Chinese, In Press].

36. SVOBODA M., DOUG L.C., HAYES M., HEIM R., GLEASON K., ANGEL J., RIPPEY B., TINKER R., PALECKI M., STOOKSBURY D., MISKUS D., STEPHENS S. The drought monitor. Bull. Amer. Mete. Soc. (8), 1181, 2002.

37. REN G.Y., GUO J. Change in pan evaporation and the influential factors over China: 1956-2000. J. Nat. Resour. 21, (1), 31, 2006 [In Chinese].

38. LIU B., XIAO Z.N., MA Z.G. Relationship between pan evaporation and actual evaporation in different humid and arid regions of China. Plateau Meteor. 29, (3), 629, 2010 [In Chinese].

39. DAI A.G., TRENBERTH K. E., QIAN T.T. A global dataset of Palmer Drought Severity Index for 1870-2002: Relationship with soil moisture and effects of surface warming. J. Hydrometeor. 5, 1117, 2004.

40. SONG Y.F., LIU Y.J., DING Y.H. A study of surface humidity changes in China during the recent 50 years. Acta Meteor. Sinica. 26, (5), 541, 2012. 
